\begin{tabular}{c}
\hline American Journal of Educational Research and Reviews \\
(ISSN:2474-9265)
\end{tabular}

\title{
Design of reverse logistics network for the end-of-life automobiles based on sustainable development
}

\section{LIU Kun, ZHANG Rong}

Institute of Logistics Science and Engineering, Shanghai Maritime University, Shanghai, 201306, China

\section{ABSTRACT}

From the point of view of sustainable development, a multi-ob${ }^{*}$ Correspondence to Author: jective mixed integer model to solve the problem of location and flow distribution of reverse logistics network of end-of-life automobiles. To reflect the various aspects of sustainable development, not only to minimize the objectives of economic cost and environmental cost, at the same time with the maximization of social benefits as the goal. Combined with the case, using the ideal point method by using lingo, it is concluded that the sustainable of scrapped automobile reverse logistics network optimization scheme. In addition, the impact of government subsidy on the sustainability of reverse logistics network is analyzed. In addition, the uncertainty of product recovery and the influence of government subsidy on the sustainable development of reverse logistics network are analyzed. The results show that end-oflife automobiles with more dismantled products have a greater impact on the sustainability of reverse logistics network, and government subsidies have an ideal interval to make the sustainability of reverse logistics network reach the best state.

Keywords: Sustainable development; end-of-life automobiles; Reverse logistics; Site selection model; Social benefits; Multi-objective optimization

Foundation projects: National Natural Science Foundation of China (71571117); Humanities and So-cial Sciences Planning Project of Ministry of Education (18YJA630143) 


\section{Introduction}

In recent years, with people's increasing attention to sustainable development and circular economy, abandoned automobile, as an important part of "urban mineral resources", have become a hot spot in the research. There are more and more abandoned cars in China, and their recyclable resources are abundant ${ }^{[1-2]}$. Therefore, it is particularly important to establish a complete waste vehicle recycling network ${ }^{[3-4]}$. In recent years, China has gradually established a series of relevant laws and regulations to promote the orderly development of scrap automobile industry. With the continuous improvement of dismantling technology of waste vehicles, many recycling companies are no longer confined to recycling only single products such as used car batteries or engines. Therefore, this model considers the location and flow distribution of various parts and raw materials at the same time.

At present, many achievements have been made in the reverse logistics network considering the economic and environmental aspects. Dong Guiying et al. ${ }^{[5]}$ establish a mixed integer programming model aiming at maximizing revenue to determine the location and flow distribution of scrap vehicle reverse logistics network. SOLVANG et al. ${ }^{\left[{ }^{6]}\right.}$ establish a stochastic optimization model aiming at cost minimization to design reverse logistics network. Yang Bin et al. ${ }^{[7]}$ establish a planning model of mobile phone recycling reverse logistics network according to the structure and processing flow of mobile phone recycling reverse logistics network, which aims at maximizing the profit of Internet mobile phone recycling enterprises and the average utilization rate of recycling and processing facilities. Zhao Fuquan et al. ${ }^{[8]}$ construct a life cycle environmental impact assessment model of automobile engine considering scrap recycling. Zhang Qun et al. ${ }^{[9]}$ aim at minimizing logistics cost and environmental impact, establish a multi-objective stochastic programming model to determine the reverse logistics network of enterprises, and use Cplex in MATLAB to solve the problem. Chen Yong et al. ${ }^{[10]}$ set up a dualobjective model aiming at maximizing profits and minimizing the negative effects of recycling centers on residents to solve the reverse logistics network planning problem of third-party scrapped household appliances recycling enterprises, and solve it with Lingo software. Yan Nannan et al. ${ }^{[11}$ establish a mathematical model aiming at minimizing total cost sum and carbon emissions to determine the location and number of facilities in the scrap vehicle reverse logistics network.

In the optimization of the reverse logistics network of scrap automobiles, the economy or the environment are mostly considered, and the social level has not received much attention. SEURING et al. ${ }^{[12]}$ define sustainability as "the design and use of human and industrial systems to utilize natural resources and to ensure that normal cycles do not have a negative impact on social conditions, human health and ecosystems". ARAMPANTZI et al. ${ }^{[13]}$ establish a mathematical model of sustainable supply chain, in which the environmental objectives are expressed by $\mathrm{CO} 2$ emissions. In order to integrate into the social objective function, various aspects of society are considered, such as the number of jobs provided, the number of facilities established in underdeveloped areas and the risk of transport accidents. SOLEIMANI et al..14] propose a mathematical model to maximize economic benefits, minimize environmental impacts and maximize social benefits to solve the network 
design problem of closed-loop supply chain, in which environmental indicators are expressed by carbon dioxide emissions and social benefits are expressed by the number of working days lost due to accidents.

Compared with the environmental dimension in previous studies, social dimension has not received much attention. Social sustainability in supply chains solves social equity and human rights issues, including human rights behavior of suppliers, working conditions, practice norms, social auditing and social equity. Sustainable reverse network design decisions can better assess the impact of an enterprise on its stakeholders, including employees, customers and local communities. Job and customer issues have been used by researchers to quantify social benefits, in which the number of jobs available is the main social indicator ${ }^{[15]}$. This paper studies the scrap automobile recycling enterprises, and establishes a multiproduct and multi-objective mathematical model to solve the problem of location and flow distribution of sustainable reverse logistics network. The sustainability of the reverse logistics network is analyzed, and the uncertainty of the recovery of various scrap vehicles and the impact of government subsidies on the sustainability of the reverse logistics network are also analyzed.

\section{Model Building}

\section{Problem Description}

Reverse logistics network structure of scrap automobile recycling and remanufacturing is shown in Figure 1. The generation area of scrap automobile; the initial collection location is mainly used to recycle all kinds of scrap automobiles; the pretreatment center mainly carries out simple detection and disassembly of scrap automobiles transported from the initial collection location; and the remanufacturing center mainly processes the dismantled products transported by the pretreatment center. It is worth noting that the remanufacturing centers here have different locations with different equipment for different kinds of parts and raw materials. Figure 1 below shows the dismantling centers with different dismantling products in circular and elliptical shapes; waste disposal plant processes non-remanufactured products; in addition, there are market customers for various parts and raw materials.

In this paper, a mixed integer programming model with multi-product and multi-objective is proposed to solve the problem of reverse logistics network planning for scrap vehicles. The economic, environmental and social aspects of sustainable development of reverse logistics are also considered. This paper takes the minimization of the economic cost of reverse logistics network as the economic objective function; in order to include the environmental aspects of network design decision-making, many indicators have been used to measure the environmental impact of supply chain, such as $\mathrm{CO} 2$ emissions, energy use and waste generation. In this paper, $\mathrm{CO} 2$ emissions from pretreatment centers and various disassembly product remanufacturing centers are taken as environmental objective functions. According to the analysis of social responsibility of scholars and international organizations at home and abroad, the most representative social indicator is job. So this paper uses the number of jobs created by the reverse logistics network to express social benefits.

\section{Model Hypothesis}

Before the establishment of the model, the following assumptions are given: (1) the 
generation area of scrap vehicles is known, and the initial collection location is in the generation area of scrap vehicles; (2) the pretreatment center simply detects and classifies the recycled scrap vehicles and does not have storage capacity; (3) the scrap vehicles can only be sent to the initial collection location, but not directly to the pretreatment center, remanufacturing treatment center and garbage treatment plant. (4) the construction cost, maximum disposal capacity and the number of jobs available at each site are known. (6) The unit processing cost of waste products is known, and the unit transportation cost is known and uniformly distributed.

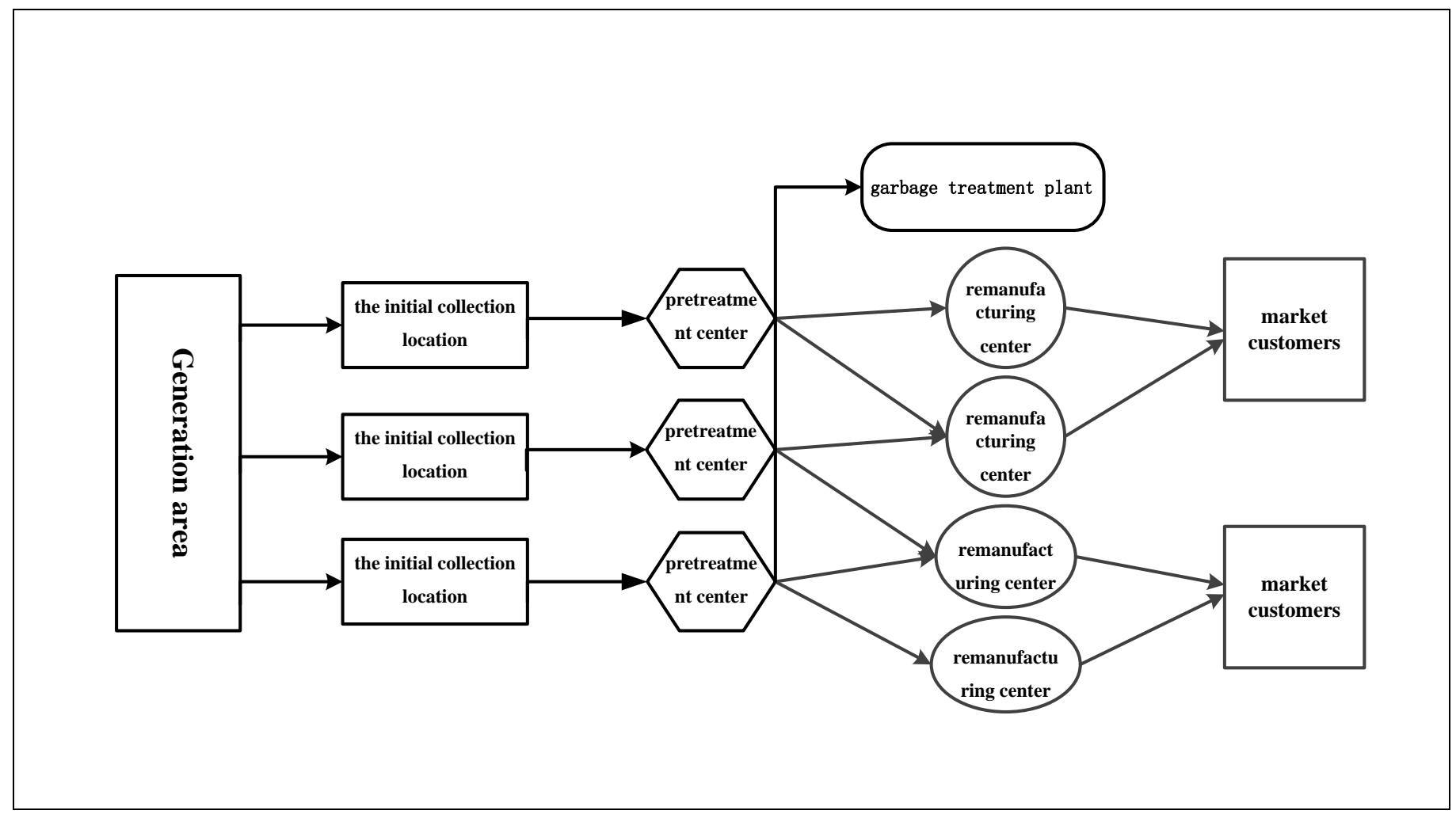

Fig. 1 Reverse logistics network structure of multi-product scrap vehicle

\section{Model Building and Solution}

\section{Model parameters and variables \\ Model parameters}

The subscripts involved in the model are: $n$ is the type of scrap vehicle, $n \in N, N$ is the collection of all types of abandoned vehicles; $u$ :categories of automobile disassembly products, $u \in U, U$ is the collection of all disassembly products for scrap vehicles; $i$ is the ordinal number for the known initial collection point, $i \in I, I$ is the collection of all initial collection point; $j$ is the serial number of pretreatment center optional location, $j \in J, J$ is the collection of all alternative locations; $k$ is the serial number of remanufacturing centre optional location, $k \in K, K$ is a collection of all remanufacturing centers; $l$ is waste disposal plant; $m$ is market customer.

The parameters involved in the model are: $s_{n}$ is the production of the $n$ type of abandoned automobile; $h_{n}$ is the recovery unit price of the $n$ type of abandoned automobile; $g_{n}$ is the subsidies for the government to recover the $n$ type of scrap automobiles; $a_{i}$ is the fixed cost for $i$ initial collection points; $a_{j}$ is the fixed cost for the pretreatment center $j ; a_{k u}$ is the 
fixed cost for remanufacturing center $k$ of type $u$ product; $b$ is the transportation cost per unit product per unit distance; $d_{i j}$ is the distance between the initial collection location $i$ and the pretreatment center $j ; d_{j l}$ is the distance between the pretreatment center $j$ and garbage disposal plant $l ; d_{j k u}$ is the distance between the pretreatment center $j$ and remanufacturing center $k$ of type $u$ product; $d_{k u m}$ is the distance between the remanufacturing center $k$ of type $u$ product and corresponding market customers $m ; c_{i}$ is the processing cost for $i$ initial collection points; $c_{j}$ is the unit processing cost for the pretreatment center $j ; c_{k u}$ is the unit processing cost of the remanufacturing center $k$ of type $u$ product; $c_{l}$ is the unit processing cost of garbage disposal plant; $m_{i}$ is the maximum processing capacity for initial collection points; $m_{j}$ is the maximum processing capacity for the pretreatment center $j ; m_{k u}$ is the processing capacity of remanufacturing center $k$ of type $u$ product; $e_{j n}$ is the unit $\mathrm{CO} 2$ emissions from $n$ scrap vehicle at the pretreatment center $j ; e_{k u}$ is the unit $\mathrm{CO} 2$ emissions of the remanufacturing center $k$ of type $u$ product; $t_{i j n}$ is the unit $\mathrm{CO} 2$ emissions from the initial collection location $i$ to the pretreatment center $j ; t_{j k u}$ is the unit $\mathrm{CO} 2$ emissions from the pretreatment center $j$ to remanufacturing center $k$ of type $u$ product; $t_{j l}$ is the $\mathrm{CO} 2$ emissions from the pretreatment center $j$ to garbage disposal plant $l ; t_{k m u}$ is the unit $\mathrm{CO} 2$ emissions from the remanufacturing center $k$ of type $u$ product to the corresponding market customers $m ; w_{i}$ is the number of jobs available for initial collection points $i ; w_{j}$ is the number of jobs available for the pretreatment center $j ; w_{k u}$ is the number of jobs available for the remanufacturing center $k$ of type product; $\alpha_{j}$ is the waste rate of pretreatment sites; $\alpha_{u}$ is the manufacturability of the disassembly product; $\gamma_{n u}$ is the proportion of $u$ dismantled products in $n$ scrap car.

\section{Decision variables}

Decision variables include $0-1$ variables and non-negative real numbers.

0-1 variables: $Z_{j}$ indicates whether to establish a pretreatment center ; $Z_{k u}$ indicates whether to establish a remanufacturing center for the $u$ disassembly product.

Non-negative real variables: $q_{i n}$ represents the disposal quantity of scrap vehicle at the initial collection location $i ; q_{j n}$ represents the disposal quantity of scrap vehicle at the pretreatment center ; $q_{l}$ represents the disposal quantity in the garbage disposal plant; $q_{k u}$ represents the disposal quantity of $u$ products at the corresponding remanufacturing treatment center; $x_{i j n}$ represents the number of abandoned vehicles of type $n$ transported from the initial collection to the pretreatment center.$x_{j l}$ indicates the quantity transported from pretreatment center to garbage disposal site; $x_{j k u}$ represents the number of dismantling products of type $u$ transported from pretreatment center to the corresponding remanufacturing treatment center $x_{k m u}$ represents the number of dismantling products of type $u$ transported from the corresponding remanufacturing treatment center to corresponding market customers

\section{Model Building Objective Function}

The three optimization objectives of this paper are to minimize the cost of reverse logistics network, minimize the environmental impact and maximize social benefits. 


$$
\begin{aligned}
\min f_{1}= & \sum_{i \in I} Z_{i} a_{i}+\sum_{j \in J} Z_{j} a_{j}+\sum_{k \in K} \sum_{u \in U} Z_{k u} a_{k u}+\sum_{i \in I} \sum_{n \in N} q_{i n}\left(c_{i}+h_{n}\right)+\sum_{j \in J} \sum_{n \in N} q_{i n} c_{j} \\
& +\sum_{k \in K} \sum_{u \in U} q_{k u} c_{k u}+\sum_{l \in L} q_{l} c_{l}+\sum_{i \in I} \sum_{j \in J} \sum_{n \in N} x_{i j n} d_{i j} b+\sum_{j \in J} \sum_{k \in K} \sum_{u \in U} x_{j k u} d_{j k} b \\
& +\sum_{k \in K} \sum_{m \in M} \sum_{u \in U} x_{k m u} d_{k m u} b+\sum_{j \in J} \sum_{l \in L} x_{j l} d_{j l} b-\sum_{i \in I} \sum_{n \in N} q_{i n} g_{n}
\end{aligned}
$$

Formula 1 represents the economic cost minimization of the scrap vehicle reverse logistics network. The first three items represent the fixed cost of the initial collection location, the pretreatment center and the remanufacturing center of the $u$ product. Items 4 and 5 represent the treatment cost and the recovery cost of the scrap vehicle at the initial collection location, respectively. Item 6 represents the disassembly cost of the pretreatment center; item 7 represents the disposal expenses of each dismantled product in its corresponding remanufacturing center; item 8 represents waste disposal cost that cannot be manufactured; items 9 to 12 represent the transportation costs of different locations; and the last represents the government subsidy expenses.

$$
\begin{aligned}
\min f_{2}= & \sum_{j \in J} \sum_{n \in N} q_{j n} e_{j n}+\sum_{k \in K} \sum_{u \in U} q_{k u} e_{k u}+\sum_{i \in I} \sum_{j \in J} \sum_{n \in N} x_{i j n} t_{i j n}+\sum_{j \in J} \sum_{l \in L} x_{j l} t_{j l} \\
& +\sum_{j \in J} \sum_{k \in K} \sum_{u \in U} x_{j k u} t_{j k u}+\sum_{k \in K} \sum_{m \in M} \sum_{u \in U} x_{k m u} t_{k m u}
\end{aligned}
$$

Formula (2) represents the minimization of carbon dioxide emissions. The first two items represent carbon dioxide emissions from pretreatment centers and remanufacturing

$$
\max f_{3}=\sum_{i \in I} p_{i} Z_{i}+\sum_{j \in J} p_{j} Z_{j}+\sum_{k \in K} \sum_{u \in U} p_{k u} Z_{k u}
$$

Form (3) represents the maximum number of jobs provided by the initial collection location, the pretreatment center and the $u$ disassembly centers for the $u$ disassembly product, and 3 to 6 items represent carbon dioxide emissions from transportation between different locations.

$$
\begin{aligned}
& s_{n}=\sum_{i \in I} q_{i n}, \forall n \in N \\
& q_{i n}=\sum_{j \in J} x_{i j n}, \forall, i \in I, n \in N \\
& q_{j n}=\sum_{i \in I} x_{i j n}, \forall, j \in J, n \in N \\
& q_{k u}=\sum_{j \in J} x_{j k u}, \forall k \in K, u \in U \\
& q_{l}=\sum_{j \in J} x_{j l}=\alpha_{j} \sum_{j \in J} \sum_{n \in N} q_{j n}, \forall l \in L \\
& \sum_{k \in K} x_{j k u}=\gamma_{n u} \sum_{n \in N} q_{j n}, \quad \forall j \in J, u \in U
\end{aligned}
$$




$$
\begin{aligned}
& \sum_{m \in M} x_{k m u}=\alpha_{u} \sum_{k \in K} q_{k u}, \quad \forall u \in U \\
& q_{i n} \leq m_{i} Z_{i}, \quad \forall i \in I, n \in N \\
& q_{j n} \leq m_{j} Z_{j}, \quad \forall j \in J, n \in N \\
& q_{k u} \leq m_{k u} Z_{k u}, \quad \forall k \in K, u \in U \\
& Z_{i}, Z_{j}, Z_{k u} \in\{0,1\}
\end{aligned}
$$

Constraint (4) indicates that the initial collection location can recover all scrap vehicles; (5) indicates that the processed quantity of $i$ initial collection point equals the number of shipments to all pretreatment centers; (6) indicates that the processed quantity of $j$ pretreatment center equals the number of all initial collection points shipped to here; (7) The number of products $u$ processed by the $u$ remanufacturing centre of the disassembly product is equal to the number of $u$ transported from all pretreatment centers; (8) the amount of transportation from the landfill is equal to the amount of garbage produced by the pretreatment center; (9) the amount of $u$ disassembly product in all the remanufacturing centers is equal to the amount of disassembly from all the scrapped cars in the pretreatment center; (10) represents the sales volume of the $u$ disassembly product equal to its production in the corresponding remanufacturing center; Formula (11) - (12) denote capacity constraints for alternative locations; formula

(14) ensures

$$
\min =\sqrt{\sum_{i=1}^{3}\left(f_{i}-f_{i}^{*}\right)^{2}}
$$

Lingo software can be used to solve linear programming problems, non-linear programming problems and mixed integer linear programming problems. It has flexible solution and strong operability. In addition, this paper defines the sub-model when using the main model in Lingo model window in version 11.0. The sub-model can be called in the that $Z_{i}, Z_{j}, Z_{k u}$ are $0-1$ variables; the remaining decision variables are non-negative variables.

\section{Solution Method}

In solving multi-objective programming problems, many experts use ant colony algorithm, particle swarm optimization and genetic algorithm and so on. The operation process of the above algorithm is rather tedious. Moreover, three objective functions are established in this paper. If the above method is used, the solving process will be more complicated. The three objective functions established in this paper have a definite ideal solution $f_{i}$ for each single objective, namely $f_{i}^{*}$. Generally speaking, there is not necessarily a solution that satisfies three objectives and achieves the optimal solution at the same time, but a solution can be found to make the three objectives as close as possible to the ideal value. The ideal point method is used to transform multiple objective functions, and the optimal compromise scheme can be obtained by formula (14).

calculation section of the main model, which further enhances Lingo's programming ability.

\section{Examples verification and analysis}

\section{Known conditions}

It is known that a scrap automobile recycling enterprise is planning to lay out a scrap automobile recycling network in a city. At 
present, the enterprise has only two types of vehicles, $A$ and $B$, and two main disassembly products: engine $V$ and scrap steel W. A car model $A$ can dismantle an engine and $50 \%$ of the scrap steel. A car model B can be disassembled into an engine and $70 \%$ waste steel. The city is divided into seven consumption areas. The amount of scrap A vehicles is $6699,1879,8841,260,1634,348$ and 451 respectively. The unit cost of recovery is 450 yuan per vehicle and the government subsidy is 1000 yuan per vehicle. The amount of scrap Bvehicles is 8846, 1900, 518, 4173, 1284, 1706 and 1674 respectively, and the unit price of recovery is 800 yuan per vehicle. The government subsidy is 2500 yuan per vehicle.

There are seven known initial collection points, five pretreatment center alternative centres, three disassembly product $\mathrm{V}$ remanufacturing center alternatives, and three disassembly product $\mathrm{W}$ remanufacturing center alternatives.
The location of the demand market of each alternative network node is generated in the two-dimensional plane of 200-500, and their Euclidean distance is calculated. The unit treatment cost of garbage treatment plant obeys the uniform distribution $U(1,2)$; the average unit transportation cost obeys the uniform distribution $U(2,3)$; and the average unit carbon dioxide emission obeys the uniform distribution $U(3,5)$. The waste rate in the pretreatment center is $15 \%$. The remanufacturing rate of $\mathrm{W}$ is $80 \%$, and that of $\mathrm{V}$ is $70 \%$. The remaining parameters are shown in the table below. In order to ensure the rationality of the numerical value, the empirical analysis for setting parameters [15] of initial collection point, pretreatment center, the remanufacturing center of disassembly product $\mathrm{V}$ and disassembly product $\mathrm{W}$ are as tables 2 to 5 , in which the unit emission of $\mathrm{CO} 2$ from each facility obeys uniform distribution.

Table 1 Specific values of parameters associated with initial collection points

\begin{tabular}{|c|c|c|c|c|}
\hline Initial collection point & Fixed cost/yuan & $\begin{array}{l}\text { Maximum processing } \\
\text { capacity/vehicle }\end{array}$ & $\begin{array}{l}\text { Unit } \quad \text { processing } \\
\text { cost/yuan }\end{array}$ & Number of jobs \\
\hline collection point 1 & 1945600 & 20000 & 142 & 204 \\
\hline collection point 2 & 1846000 & 10000 & 105 & 269 \\
\hline collection point 3 & 1481550 & 15000 & 85 & 291 \\
\hline collection point 4 & 1828750 & 16000 & 108 & 201 \\
\hline collection point 5 & 1663860 & 15000 & 97 & 204 \\
\hline collection point 6 & 1794250 & 15000 & 113 & 254 \\
\hline collection point 7 & 1301360 & 18000 & 78 & 217 \\
\hline
\end{tabular}

Table 2 Specific values of relevant parameters for alternative sites in pretreatment sites

\begin{tabular}{|l|l|l|l|l|l|}
\hline $\begin{array}{l}\text { Pretreatment } \\
\text { location }\end{array}$ & $\begin{array}{l}\text { Fixed } \\
\text { cost/yuan }\end{array}$ & $\begin{array}{l}\text { Maximum } \\
\text { processing } \\
\text { capacity/vehicl } \\
\mathrm{e}\end{array}$ & $\begin{array}{l}\text { Unit processing } \\
\text { cost/yuan }\end{array}$ & Number of jobs & $\begin{array}{l}\text { CO2 emissions } \\
\mathrm{kg} / \text { vehicle }\end{array}$ \\
\hline Option 1 & 867970 & 20000 & 277 & 156 & $\mathrm{U}(20,30)$ \\
\hline Option 2 & 926341 & 18000 & 291 & 180 & $\mathrm{U}(20,30)$ \\
\hline Option 3 & 972806 & 20000 & 286 & 176 & $\mathrm{U}(20,30)$ \\
\hline Option 4 & 875900 & 19000 & 221 & 166 & $\mathrm{U}(20,30)$ \\
\hline Option 5 & 889289 & 19000 & 267 & 177 & $\mathrm{U}(20,30)$ \\
\hline
\end{tabular}


Table 3 Specific values of relevant parameters for disassembly products $V$ alternative locations

\begin{tabular}{|l|l|l|l|l|l|}
\hline $\begin{array}{l}\text { V Remanufacturin } \\
\text { g Center } \\
\text { Location }\end{array}$ & Fixed cost/yuan & $\begin{array}{l}\text { Maximum } \\
\text { processing } \\
\text { capacity/vehicle }\end{array}$ & $\begin{array}{l}\text { Unit processing } \\
\text { cost/yuan }\end{array}$ & Number of jobs & $\begin{array}{l}\text { CO2 emissions } \\
\mathrm{kg} / \text { piece }\end{array}$ \\
\hline Option 1 & 3464123 & 10000 & 456 & 288 & $\mathrm{U}(8,15)$ \\
\hline Option 2 & 3168031 & 15000 & 479 & 265 & $\mathrm{U}(8,15)$ \\
\hline Option 3 & 3396932 & 10000 & 469 & 251 & $\mathrm{U}(8,15)$ \\
\hline
\end{tabular}

Table 4 Specific values of relevant parameters for disassembly products $\mathrm{W}$ alternative locations

\begin{tabular}{|l|l|l|l|l|l|}
\hline $\begin{array}{l}\text { Remanufacturin } \\
\text { L Center } \\
\text { Location }\end{array}$ & $\begin{array}{l}\text { Fixed } \\
\text { cost/yuan }\end{array}$ & $\begin{array}{l}\text { Maximum } \\
\text { processing } \\
\text { capacity/vehicle }\end{array}$ & $\begin{array}{l}\text { Unit processing } \\
\text { cost/yuan }\end{array}$ & Number of jobs & $\begin{array}{l}\text { CO2 emissions } \\
\mathrm{kg} / \text { piece }\end{array}$ \\
\hline Option 1 & 2180655 & 20000 & 252 & 343 & $\mathrm{U}(10,20)$ \\
\hline Option 2 & 2357450 & 30000 & 252 & 379 & $\mathrm{U}(10,20)$ \\
\hline Option 3 & 2240518 & 25000 & 274 & 331 & $\mathrm{U}(10,20)$ \\
\hline
\end{tabular}

\section{Result Analysis}

From the data in the above table, the optimal values of three single objectives are obtained by Lingo 11.0. The optimal economic objective function is 97.44 million, the optimal value of environmental objective function is 0.837 million, and the optimal value of social benefit objective is 4352. The optimal values of three single targets are substituted into formula (15) and solved by Lingo 11.0 software. The Pareto optimal solution of three objectives and the location scheme are obtained. The economic cost of this scrap vehicle reverse logistics network is 9.88 million yuan; the emission of $\mathrm{CO} 2$ is 84.3 million tons; the number of jobs available is 3412 .

The alternative points of $j$ pretreatment centers of this reverse logistics network are 1,3,5, and their processing capacity is 1213,20000 and 19000 respectively. The remanufacturing centers for disassembled products $\mathrm{V}$ are 2 and 3 , and their processing capacity are 28995 and 2170 , respectively. The remanufacturing centers for disassembled products $\mathrm{W}$ are 1 and
2 , with processing capacity of 1888 and 15000 respectively. The processing values of all the selected nodes are generated under the maximum capacity. The processing capacity of some locations differs from that of other locations, which is consistent with the actual situation. The volume of transport of initial collection points, pretreatment centers, remanufacturing centers for dismantled products $\mathrm{V}$ and $\mathrm{W}$ is shown in Table 6 below. In addition, the disposal capacity of garbage treatment plant is 3114 , the total amount of dismantled product $\mathrm{V}$ transported to the market is 22519, and the total amount of dismantled product $\mathrm{W}$ transported to the market is 13510 .

In this paper, besides considering economic costs, the objective of minimizing environmental impact and maximizing social benefits is added to the model. The constraints and objective functions are increased correspondingly. Therefore, the final result is that the effective solution obtained by considering the overall optimum of the three objective functions, and it is Pareto optimum solution. 
Table 5 Transportation Volume in the Reverse Logistics System of Waste Vehicles

\begin{tabular}{|l|l|l|l|}
\hline$i, j$ & Volume & $j, k 1$ & Volume \\
\hline 1,3 & 13345 & 3,2 & 16416 \\
\hline 2,3 & 2221 & 3,3 & 1079 \\
\hline 2,5 & 3758 & 5,2 & 12579 \\
\hline 3,1 & 1213 & 5,3 & 1091 \\
\hline 3,5 & 8146 & $j, k 2$ & Volume \\
\hline 4,3 & 4434 & 1,1 & 461 \\
\hline 5,5 & 2918 & 5,1 & 1427 \\
\hline 6,5 & 2054 & 3,2 & 5817 \\
\hline 7,5 & 2124 & 5,2 & 6432 \\
\hline
\end{tabular}

Note: $k 1$ represents the remanufacturing center of $\mathrm{V}$ and $k 2$ represents the remanufacturing center of $\mathrm{W}$.

\section{Sustainability Analysis}

This paper is a model to establish a sustainable reverse logistics network for scrap automobile industry. Sustainability requires that the economic, environmental and social objectives of the reverse logistics network model be optimized at the same time. To verify the sustainability of the reverse logistics network model in this paper, we compare three scenarios: scenario 1: economic cost minimization is the only objective function; scenario 2: objective function includes economic cost minimization and environmental impact minimization; scenario 3: The objective functions include minimizing economic costs, minimizing environmental impacts and maximizing social benefits. Under these three scenarios, the economic costs, $\mathrm{CO} 2$ emissions and the number of jobs available are shown in Figure 2 below.

As shown in Fig. 2a) Scenario 1, when the reverse logistics network only considers the economic cost, the minimum economic cost is 9.74 million yuan, but the negative impact of the environment at this time is the greatest, that is, the maximum emission of $\mathrm{CO} 2$ is 0.854 million tons as shown in Fig. 2b) Scenario 1. The social benefit is the lowest, that is, the minimum number of jobs provided is 2,377 as shown in Fig. 2c) Scenario 1. Considering the economic cost and environmental impact, as shown in Fig. 3 , scenario 2, the economic cost has increased, but the negative impact of the environment has declined at a higher rate, and the social benefits have increased, which is conducive to the low-carbon development of the reverse logistics network. As shown in Fig. 3 Scenario 3, at this time, the economic cost is higher than the first two scenarios, but the environmental impact is lower and the social benefit is higher. This shows that the model in this paper is conducive to the sustainable development of the reverse logistics network.

\section{Sensitivity Analysis}

\section{The Impact of Government Subsidies}

This chapter studies the impact of government subsidies on network design. Increase government subsidies on the original basis by $40 \%,-20 \%,-10 \%, 10 \%, 20 \%, 40 \%$; Other parameters remain unchanged. The economic costs, $\mathrm{CO} 2$ emissions and the number of jobs available in reverse logistics network for scrapped vehicles under these seven scenarios are analyzed in Table 6. 
LIU Kun, ZHANG Rong, AJERR, 2019;4:58

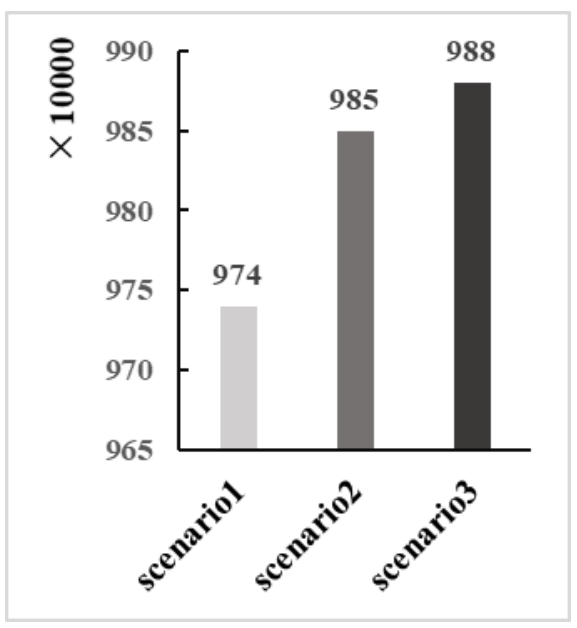

a) Economic cost in three scenarios

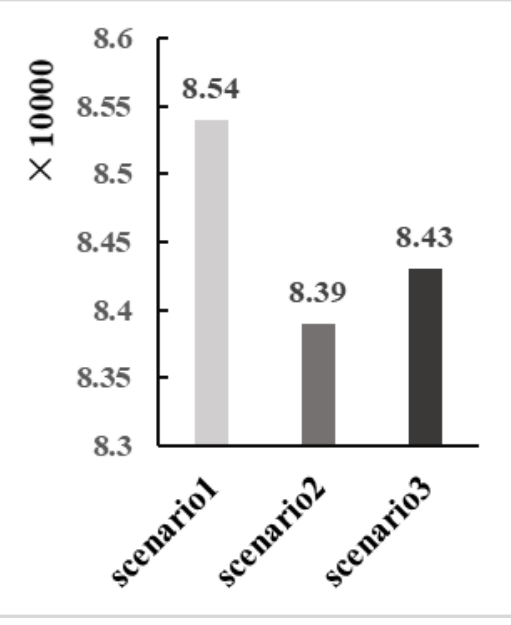

b) $\mathrm{CO} 2$ emissions in three scenarios

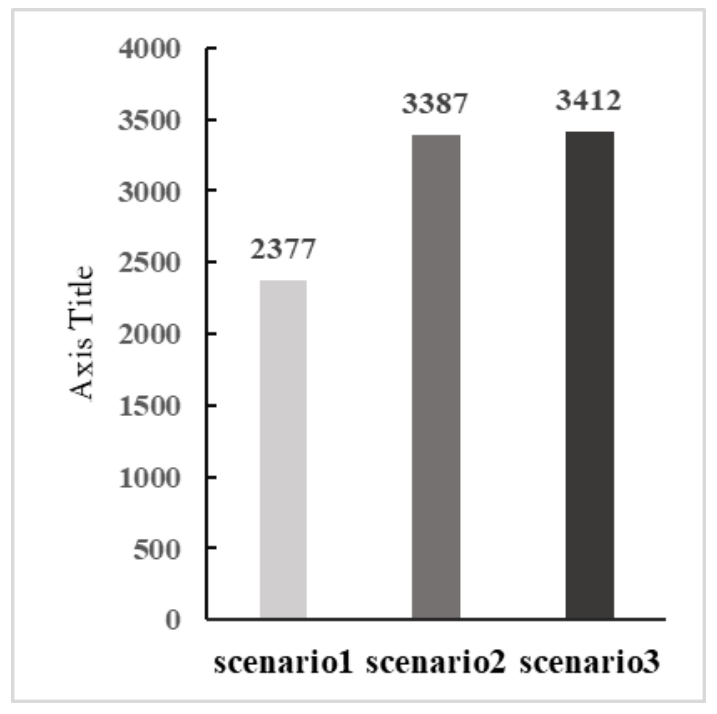

c) Number of jobs in three scenarios

Figure 2 Target values in three scenarios

Table 6 Impact of Government Subsidies on the Sustainability of Reverse Logistics Networks

\begin{tabular}{|l|l|l|l|}
\hline $\begin{array}{l}\text { Government subsidy/yuan per } \\
\text { vehicle }\end{array}$ & $\begin{array}{l}\text { Economic cost/10,000 } \\
\text { yuan }\end{array}$ & $\begin{array}{l}\text { CO2 emissions/10,000 } \\
\text { tons }\end{array}$ & Number of jobs \\
\hline$-40 \%$ & 1034 & 8.74 & 3779 \\
\hline$-20 \%$ & 1125 & 8.69 & 3718 \\
\hline$-10 \%$ & 1133 & 8.57 & 3400 \\
\hline basic & 988 & 8.43 & 3412 \\
\hline$+10 \%$ & 1138 & 8.59 & 4006 \\
\hline$+20 \%$ & 1138 & 8.59 & 4006 \\
\hline$+40 \%$ & 1130 & 8.54 & 3614 \\
\hline
\end{tabular}


The economic costs, $\mathrm{CO} 2$ emissions and the number of jobs available in reverse logistics network for scrapped vehicles under different scenarios are shown in Figure 4.

(1)As shown in Fig. 4a), economic costs do not decrease with the increase of government subsidies. On the right side of the government's basic subsidy, the economic cost will increase with the increase of government subsidy, because the increase of government subsidy encourages enterprises to make large-scale recovery, at this time, the scale economy is formed, and the economic cost tends to balance gradually. On the left side of the government's basic subsidy, the economic cost will decrease as the government subsidy decreases, because the less the government subsidy, the less the enterprise's enthusiasm, and the amount of recovery will reduce, at this time the economic cost is naturally low.

(2)As shown in Fig. 4b), on the right side of the government's basic subsidy, the trend of environmental impact, i.e. CO2 emissions, is similar to that of economic costs, which increases with the increase of government subsidies and then tends to be balanced. But on the left side of the government's basic subsidy, the emission of $\mathrm{CO} 2$ increases with the reduction of government subsidy, because the enterprises' enthusiasm for recycling is low, and their enthusiasm for green production is also low.

(3)As shown in Figure 4c), on the right side of the government's basic subsidy, the trend of social benefits, i.e. the number of jobs provided by the government, is the same as that of the former two, which increases with the increase of government subsidy and then tends to balance. On the left side of the basic government subsidy, the number of jobs available increases with the reduction of government subsidy. Because the reduction of government subsidies makes enterprises less motivated and employees less efficient.

(4)By comparing the effects of government subsidies on economic costs, environmental impacts and the number of jobs available, we can see that government subsidies have increased by $10 \%$ to $20 \%$ on the original basis to form economies of scale, and the sustainability of reverse logistics network has reached a stable state.

\section{The influence of different recoveries}

Uncertainty of recovery is the inherent characteristic of reverse logistics network. This paper considers the impact of different recoveries on sustainable reverse logistics network. The recovery of abandoned automobile model $A$ and abandoned automobile model $B$ is set to three grades: low, medium and high. Among them, the recoveries of model A are 10,000, 20,000 and 30,000 respectively, and those of model $B$ are 10,000, 20,000 and 30,000 respectively. The effects of these two types of vehicles on the economic cost, $\mathrm{CO} 2$ emissions and the number of jobs available in the reverse logistics network of scrap vehicles in nine scenarios are studied.

The three target values for the analysis of two kinds of scrap vehicles with different recycling amounts are shown in Table 7. As can be seen from table 7:

(1)When the number of scraped vehicles $A$ and $B$ reaches 30,000 at the same time, that is to say, both of them have high recovery, the model has no effective solution. Because the amount of recovery at this time has been higher than the maximum processing capacity of this scrap vehicle reverse logistics network. It can be imagined that the recycling of scrap cars is not the higher the better, but should be within its disposable range.

(2)When the recovery of scrap vehicle type $A$ is 10000, the economic cost first decreases and then increases with the increase of the recovery of scrap vehicle type $B$, the reduction and increase rates are $32 \%$ and $36 \%$, respectively. When the recovery of scrap vehicle type $B$ is 10000 , the economic cost first decreases and then increases with the increase of the recovery of abandoned vehicle type A, respectively. $12 \%$ 
LIU Kun, ZHANG Rong, AJERR, 2019; 4:58

and $23 \%$. It can be seen that the recovery of cost than that of scrap vehicle $B$ on economic scrap vehicle $A$ has less impact on economic cost.

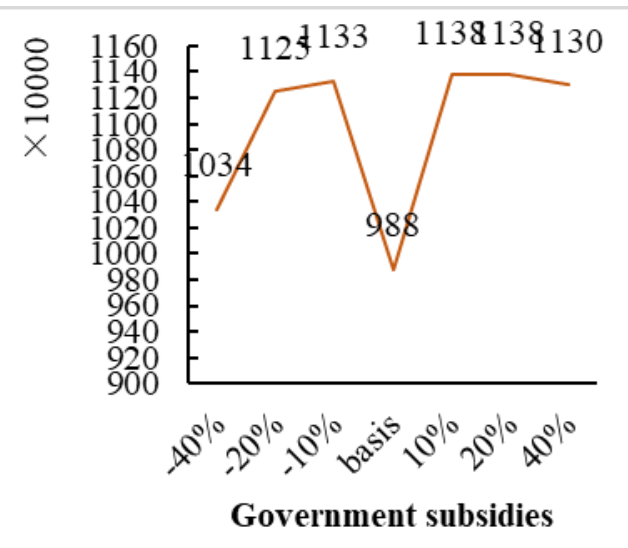

a)The Impact of Government Subsidies on Economic Costs

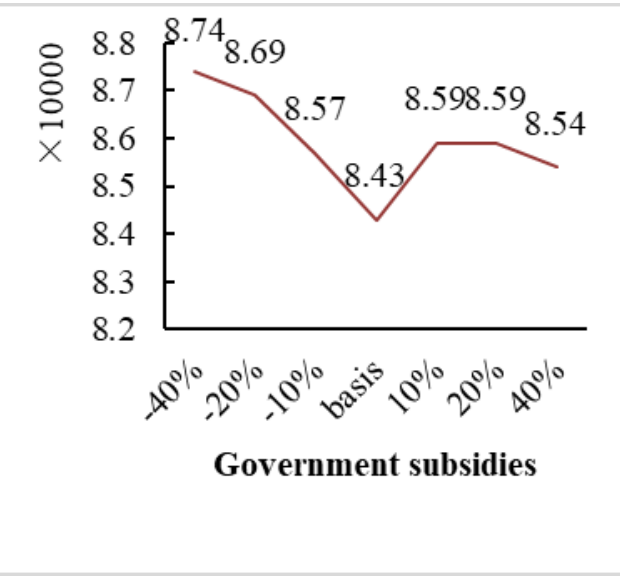

b)The Impact of Government Subsidies on CO2 Emissions

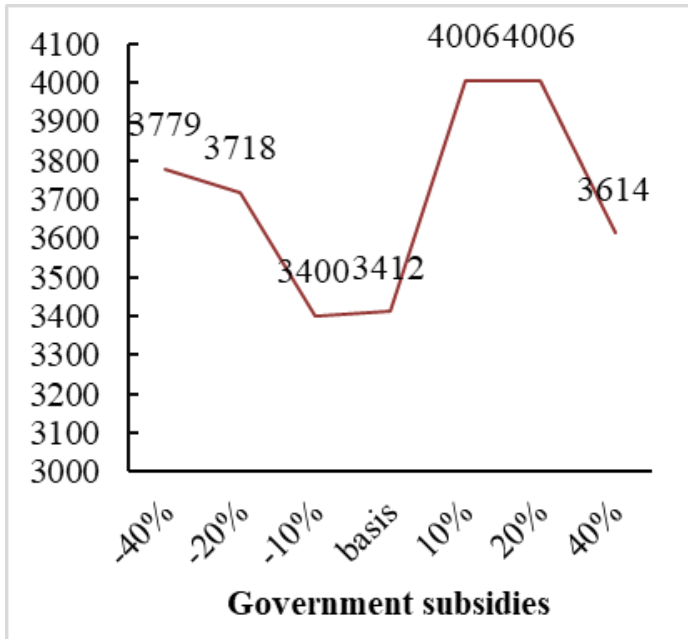

c)The Impact of Government Subsidies on the Number of Jobs

Figure 3 The impact of government subsidies on three objectives

Table 7 The impact of two kinds of scrap vehicle recovery on the sustainability of reverse logistics network

\begin{tabular}{|l|l|l|l|l|}
\hline \multirow{2}{*}{$\begin{array}{l}\text { Recovery of A / } \\
\text { Vehicle }\end{array}$} & $\begin{array}{l}\text { Recovery of B/ } \\
\text { Vehicle }\end{array}$ & $\begin{array}{l}\text { Economic cost/ } \\
10,000 \text { yuan }\end{array}$ & $\begin{array}{l}\text { CO2 emissions/ } \\
10,000 \text { tons }\end{array}$ & Number of jobs \\
\hline \multirow{3}{*}{10000} & 10000 & 978 & 4.12 & 4352 \\
\hline \multirow{3}{*}{20000} & 20000 & 663 & 6.41 & 2905 \\
\cline { 2 - 5 } & 30000 & 904 & 8.89 & 3420 \\
\hline \multirow{3}{*}{30000} & 10000 & 857 & 5.53 & 3013 \\
\cline { 2 - 5 } & 20000 & 723 & 9.82 & 2809 \\
\cline { 2 - 5 } & 30000 & 1298 & 10.76 & 4102 \\
\hline & 10000 & 1059 & 7.56 & 3365 \\
\hline & 20000 & 1362 & 10.79 & 4352 \\
\hline
\end{tabular}


(3)When the recovery of abandoned vehicle type $A$ is 10000 , the CO2 emission increases with the increase of the recovery of abandoned vehicle type $B$, the increase rates are $55 \%$ and $38 \%$, respectively. When the recovery of abandoned vehicle type B is 10000 , the CO2 emission increases with the increase of the recovery of abandoned vehicle type $A$, the increase rates are $34 \%$ and $36 \%$, respectively. The effect of recycling amount of scrap vehicle A on $\mathrm{CO} 2$ emission is less than that of recycling amount of scrap vehicle $\mathrm{B}$ on $\mathrm{CO} 2$ emission.

(4)When the recovery of abandoned automobile type $A$ is 10,000 , the number of jobs provided decreases first and then increases with the increase of the recovery of abandoned automobile type $\mathrm{B}$, the reduction and increase rates are $33 \%$ and $18 \%$ respectively; when the recovery of abandoned automobile type $B$ is 10,000 , the number of jobs provided decreases first and then increases with the increase of the recovery of abandoned automobile type A.The reduction rate and the increase rate are $30 \%$ and $12 \%$, respectively. It can be seen that the effect of the recovery of abandoned automobile type $A$ on the number of jobs is less than that of abandoned automobile type $B$ on the number of jobs.

(5) Economic costs, $\mathrm{CO} 2$ emissions and the number of jobs available increase with the increase of the total recovery of scrap vehicles, but the impact of different recovery of scrap vehicles $\mathrm{A}$ on economic costs, $\mathrm{CO} 2$ emissions and the number of jobs is less than that of scrap vehicles $\mathrm{B}$ on economic costs, $\mathrm{CO} 2$ emissions and the number of jobs. And the impact of the number of jobs. This is because the number of disassembly products of abandoned automobile model $B$ is more than that of abandoned automobile model $\mathrm{A}$.

\section{Conclusion}

From the perspective of sustainable development, this paper designs a multiproduct and multi-component reverse logistics network structure for scrap automobile recycling enterprises. In the design of the model, not only the minimization of the cost of reverse logistics network and the minimization of environmental impact are considered, but also the maximization of social benefits is considered. A multi-objective programming model is established. It not only reduces the logistics and environmental costs of enterprises, but also improves their sense of social responsibility, so as to provide sustainable competitive advantages for enterprises. Although based on the above two points, it is more difficult to build and solve the model. However, this paper takes the scrap automobile industry as the analysis objective, uses the ideal point method to solve the problem with Lingo programming software, verifies the feasibility and validity of the model, and analyses the sustainability of the reverse logistics network. In addition, the effects of different recoveries of different products and government subsidies on the sustainability of reverse logistics network are analyzed. The results show that scrap vehicles with a large number of dismantled products have a greater impact on the sustainability of reverse logistics network, and government subsidies have an ideal interval to make the sustainability of reverse logistics network reach the best state.

Due to the wide and complex nature of social problems, it is difficult to measure all aspects of social responsibility. This paper is not comprehensive enough in expressing social benefits only by the representative social indicators, i.e. the number of jobs offered. In the future, the quantification of social indicators should be further studied.

Foundation projects: National Natural Science Foundation of China (71571117); Humanities and Social Sciences Planning Project of Ministry of Education (18YJA630143);

Author's brief introduction: Liu Kun (1994-), female, Huaibei, Anhui Province, graduate student, research direction for free trade zone and supply chain management, (E-mail) 18916088336@163.com;

Zhang Rong: (1973-) Female, Beijing native, 
associate professor, master's supervisor, research direction for logistics and supply chain management,

(E-mail)

zhangrong@shmtu.edu.cn.

\section{Reference:}

1. Chen Yuanhua, Yang Yanping, Xie Linming, et al. Analysis of the present situation of recycling and utilization of scrap automobiles in China and suggestions for countermeasures [J]. China Engineering Science, 2018,20(1): 113-119.

2. Tian Guangdong, Jia Hongfei, Chu Jiangwei. Theory and practice of automobile recycling [M]. Beijing: Science Publication, 2016:274.

3. Zhang Qun, Wei Li Rong. Research Progress of Reverse Logistics Network Design [J]. Chinese Management Science, 2016, 24 (9): 165-176.

4. Zhou Yuhong, Jiang Chaoyang. Preliminary study on the framework of automobile scrap recycling system in China [J]. Environmental Science and Technology, 2006, 29 (3): 94-96.

5. Dong Guiying, Hu Jiankun, Huang Youfang. Optimization of reverse logistics network model for scrap automobile remanufacturing [J]. Shanghai Maritime University, 2018, 39 (1): 6066.

6. Hao Yu, Wei Deng Solvang. A carbonconstrained stochastic optimization model with augmented multi-criteria scenario-based riskaverse solution for reverse logistics network design under uncertainty[J]. Journal of Cleaner Production, 2017,164:1248-1267.

7. Ling Xu, Yang Bin, Zhu Xiaolin. Design of reverse logistics network for discarded mobile phones under the background of "Internet +" [J]. Journal of Guangxi University (Natural Science Edition), 2016,41 (5): 1465-1476.

8. Zhao Fuquan, Chen Yisong, Liu Zongwei, et al. Study on Life Cycle Environmental Impact Assessment of Vehicle Engines Considering Waste Recovery [J]. Environmental Science and Technology, 2016,39(12): 189-193.

9. Zhang Qun, Wei Li Rong. Multi-objective stochastic programming model for reverse logistics network design [J]. Soft Science, 2015, 29 (10): 120-124.

10. Chen Yong, Yang Yabin, Zhang Qin. Reverse Logistics Network Design of Waste Household Appliances Based on Third Party Recycling[J]. Mathematical Practice and Understanding, 2016,46(7): 82-89.

11. Yan Nannan, Li Ming. Site Selection of Reverse Logistics Network for Waste Vehicles Based on

https://escipub.com/american-journal-of-educational-research-and-reviews/
Low Carbon [J]. Journal of Chongqing Jiaotong University (Natural Science Edition), 2016, 35 (5): 180-184.

12. Christina Arampantzi, loannis Minis. A new model for designing sustainable supply chain networks and its application to a global manufacturer[J]. Journal of Cleaner Production,2017,156:276-292.

13. Stefan Seuring, Martin Muiier. From a literature review to a conceptual framework for sustainable supply chain management[J]. Journal of Cleaner Production, 2008,16(15):1699-1710.

14. Hamed Soleimani, Kannan Govindanatal. Fuzzy multi-objective sustainable and green closedloop supply chain network design[J]. Computers \& Industrial Engineering,2017,109: 191-203.

15. Eskandarpour M, Dejax P, Miemczyk J, et al. Sustainable supply chain network design: An optimization-oriented review[J]. Omega, 2015, 54:11-32.

16. Yan Rong. Research on the optimization of reverse logistics network for automobile remanufacturing under the third-party recycling mode [D]. Wuhan: Jianghan University, 2017.

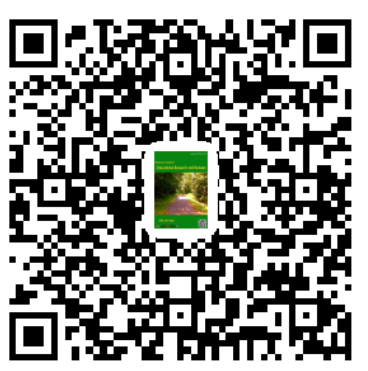

